University of Nebraska - Lincoln

DigitalCommons@University of Nebraska - Lincoln

Effects of historical climate change, habitat connectivity, and vicariance on genetic structure and diversity across the range of the red tree vole (Phenacomys longicaudus) in the Pacific Northwestern United States

Mark P. Miller

Utah State University, markperrymiller@gmail.com

M. Renee Bellinger

Oregon State University

Eric D. Forsman

U.S. Forest Service

Susan M. Haig

U.S. Geological Survey, Susan_Haig@usgs.gov

Follow this and additional works at: https://digitalcommons.unl.edu/usgsstaffpub

Miller, Mark P.; Bellinger, M. Renee; Forsman, Eric D.; and Haig, Susan M., "Effects of historical climate change, habitat connectivity, and vicariance on genetic structure and diversity across the range of the red tree vole (Phenacomys longicaudus) in the Pacific Northwestern United States" (2006). USGS Staff -Published Research. 686.

https://digitalcommons.unl.edu/usgsstaffpub/686

This Article is brought to you for free and open access by the US Geological Survey at DigitalCommons@University of Nebraska - Lincoln. It has been accepted for inclusion in USGS Staff -- Published Research by an authorized administrator of DigitalCommons@University of Nebraska - Lincoln. 


\title{
Effects of historical climate change, habitat connectivity, and vicariance on genetic structure and diversity across the range of the red tree vole (Phenacomys longicaudus) in the Pacific Northwestern United States
}

\author{
MARK P. MILLER,* M. RENEE BELLINGER,†§ERIC D. FORSMAN $\ddagger$ andSUSAN M. HAIG† \\ *Department of Biology, Utah State University, Logan, Utah 84322, USA, +USGS Forest, and Rangeland Ecosystem Science Center, \\ 3200 SW Jefferson Way, Corvallis, Oregon 97331, USA, ‡U.S. Forest Service Pacific Northwest Research Station, 3200 SW Jefferson \\ Way, Corvallis, Oregon 97331, USA
}

\begin{abstract}
Phylogeographical analyses conducted in the Pacific Northwestern United States have often revealed concordant patterns of genetic diversity among taxa. These studies demonstrate distinct North/South genetic discontinuities that have been attributed to Pleistocene glaciation. We examined phylogeographical patterns of red tree voles (Phenacomys longicaudus) in western Oregon by analysing mitochondrial control region sequences for 169 individuals from 18 areas across the species' range. Cytochrome $b$ sequences were also analysed from a subset of our samples to confirm the presence of major haplotype groups. Phylogenetic network analyses suggested the presence of two haplotype groups corresponding to northern and southern regions of $P$. longicaudus' range. Spatial genetic analyses (SAMOvA and Genetic Landscape Shapes) of control region sequences demonstrated a primary genetic discontinuity separating northern and southern sampling areas, while a secondary discontinuity separated northern sampling areas into eastern and western groups divided by the Willamette Valley. The North/South discontinuity likely corresponds to a region of secondary contact between lineages rather than an overt barrier. Although the Cordilleran ice sheet (maximum 12 000 years ago) did not move southward to directly affect the region occupied by $P$. longicaudus, climate change during glaciation fragmented the forest landscape that it inhabits. Signatures of historical fragmentation were reflected by positive associations between latitude and variables such as Tajima's $D$ and patterns associated with location-specific alleles. Genetic distances between southern sampling areas were smaller, suggesting that forest fragmentation was reduced in southern vs. northern regions.
\end{abstract}

Keywords: interpolation, mitochondrial control region, Phenacomys longicaudus, phylogeography, Pleistocene glaciation, spatial genetic analysis

Received 6 May 2005; revision received 10 August 2005; accepted 1 September 2005

\section{Introduction}

The northwestern United States has increasingly been the topic of phylogeographical analyses (e.g. Demboski \& Sullivan 2003; Monsen \& Blouin 2003; Mahoney 2004;

Correspondence: Mark P. Miller, Fax: 1+435-797-1575; E-mail: mark.miller@usu.edu.

§Present address: Hatfield Marine Science Center, Oregon State University, 2030 SE Marine Science Dr, Newport, OR 97365, USA
Pfrender et al. 2004; Kuchta \& Tan 2005; see Soltis et al. 1997 and Brunsfeld et al. 2001 for reviews). The Klamath-Siskiyou region (Fig. 1), in particular, has received considerable attention due to its impressive biological diversity (Whittaker 1961; Bury \& Perl 1999; DellaSala et al. 1999), as well as for the growing body of literature addressing interesting concordant patterns of phylogeographical structure among a wide variety of taxa (Soltis et al. 1997; Brunsfeld et al. 2001; Nielson et al. 2001; Wilke \& Duncan 2004). Of substantial interest are the multiple continuously distributed plant and 


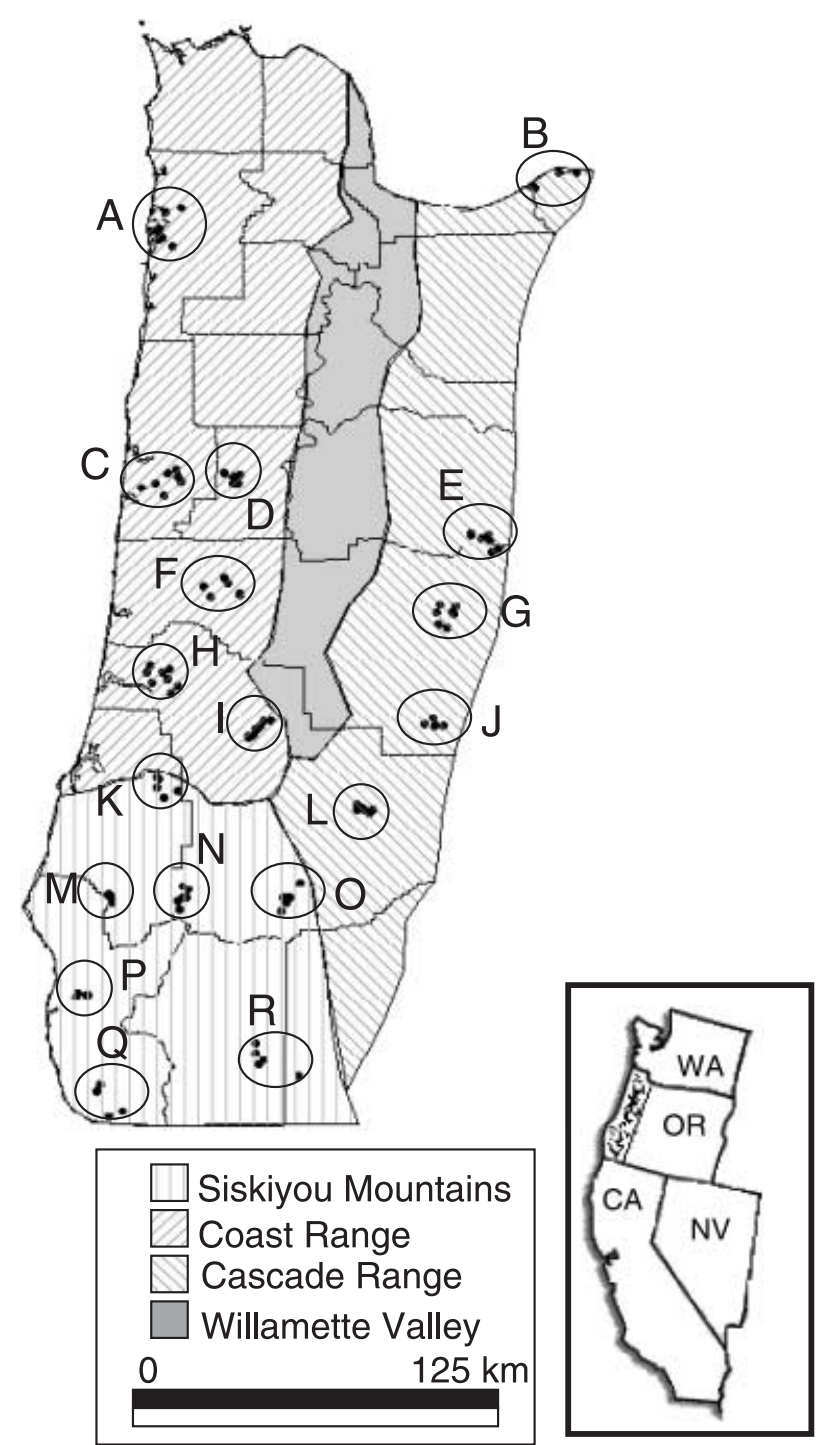

Fig. 1 Map illustrating the 18 western Oregon locations examined in this study. General locations of major physiographic provinces of western Oregon are indicated by different shading patterns (modified from Franklin \& Dyrness 1988).

animal taxa inhabiting northern California through the remainder of the Pacific Northwest that often demonstrate dramatic North/South genetic discontinuities (reviewed by Soltis et al. 1997 and Brunsfeld et al. 2001; the latter also containing additional hypotheses to include both coastal western North America and the inland northern Rocky Mountains).

Soltis et al. (1997) convincingly argued that Pleistocene glaciation events were the most likely determinant for observed phylogeographical patterns in plants and some animals from the Pacific Northwest and offered two hypotheses that were consistent with their observations. Under the North-South recolonization hypothesis (a subset of the 'Multiple Refugia' hypothesis proposed for Cascade/Sierran species in Brunsfeld et al. 2001), individuals persisted during periods of glaciation in areas to the south of the glacial maximum and in distinct nonglaciated refugia within more northern regions. Following glacial retreat, separately evolved northern and southern lineages came into secondary contact to produce the distinct North/South discontinuities observed among the species examined. In contrast, the Leading Edge hypothesis suggests that only individuals south of the glacial maximum persisted during periods of dramatic climate change. In this case, species' ranges expanded northward following glacial retreat, with only a subset of the allelic variation expanding in concert through a series of long distance dispersal events facilitated by individuals at the 'leading edge' of the range expansion. Recent simulation studies have clearly demonstrated that phylogeographical breaks can emerge despite the absence of strict geographical barriers (Irwin 2002), thus lending credence to the plausibility of the Leading Edge hypothesis. Under both hypotheses, northern populations likely experienced genetic bottlenecks. In the case of the North-South recolonization hypothesis, genetic variation is reduced in northern refugial regions due to habitat fragmentation and population isolation. Under the Leading Edge hypothesis, genetic variation is reduced in northern regions due to the effects of stochastic processes during the range expansion event.

The red tree vole (Phenacomys longicaudus $=$ Arborimus longicaudus) is endemic to a wide variety of physiographic provinces in western Oregon (and a very small part of northern California), where it occurs primarily in forests of Douglas fir (Pseudotsuga menziesii), western hemlock (Tsuga heterophylla) and Sitka spruce (Picea sitchensis) (Maser et al. 1981; Verts \& Carraway 1998; Forsman et al. 2004a, b; Fig. 1). Given its restricted range, phylogeographical analyses of this taxon present a unique opportunity to study genealogical concordance given that many of the genetic discontinuities previously observed among taxa (Soltis et al. 1997; Brunsfeld et al. 2001) are primarily located within the geographical range of $P$. longicaudus. Presently there are two recognized subspecies of $P$. longicaudus based on slight cranial and pelage differences (Howell 1926; Johnson 1968; Hall 1981). Phenacomys longicaudus silvicola is slightly darker in colour and inhabits areas including Tillamook and Lincoln Counties (corresponding to areas A and C in this study; Fig. 1), while P. l. longicaudus is slightly redder and occupies the remainder of the range (Verts \& Carraway 1998). P. l. silvicola was once considered a separate species from $P$. longicaudus, but was relegated to subspecies status due to similarities based on allozymes (Johnson 1968). More recently, phylogenetic analyses of Phenacomys detected no consistent differences between subspecies and indicated that subspecific statuses need further investigation (Bellinger et al. 2005).

Phenacomys longicaudus is one of the most specialized mammals in North America, living in nests in the forest canopy and existing almost exclusively on a diet of conifer 
needles (Verts \& Carraway 1998). It is considered to be particularly vulnerable to extirpation as a consequence of human changes to the environment because of its small home range, low dispersal capability, and sensitivity to stand-level disturbance relative to other small mammals (Maser et al. 1981; Carey 1989; Huff et al. 1992). Furthermore, this species is an important food source for the federally endangered northern spotted owl (Strix occidentalis caurina; Forsman et al. 1984; Verts \& Carraway 1998; Forsman et al. $2004 a, b)$. Concern that clear-cutting and thinning of forests might negatively impact $P$. longicaudus (and spotted owls both directly and indirectly) led to its listing as the only mammal included in the 'Survey and Manage' portion of the Northwest Forest Plan (USDA Forest Service and USDI Bureau of Land Management 2000). Thus, understanding genetic structure in $P$. longicaudus will be important for future conservation planning.

In this study, we used sequence data from the mitochondrial DNA (mtDNA) control region and cytochrome $b$ gene to obtain information on phylogeographical patterns in $P$. longicaudus across its range. We applied a number of different phylogenetic and spatial genetic analyses that allowed us to relate our data to patterns of historical climate change and physiogeographic features in western Oregon.

\section{Methods}

\section{Sample collection}

We obtained 169 samples of Phenacomys longicaudus from four different sources: tail snips from live specimens $(n=33)$, dried museum tissue $(n=7)$, frozen museum tissue $(n=9)$, and bones from regurgitated pellets of spotted owls $(n=$ 120). Six to 12 specimens were collected from 18 sampling locations throughout $P$. longicaudus's range (Fig. 1, Table 1, Appendix). Sampling areas were defined as a group of individual samples collected within an $8-\mathrm{km}$ radius of an area without an obvious geographical barrier such as a river or mountain peak. Tail snips from live voles were obtained by climbing trees, hand capturing individual voles, snipping off approximately $1 \mathrm{~cm}$ of the tip of the tail and placing each snip into a 1.5-mL cryogenic tube filled with $1 \mathrm{~mL}$ of tissue storage buffer $(100 \mathrm{~mm}$ Tris- $\mathrm{HCl} \mathrm{pH} 8$, $100 \mathrm{~mm}$ EDTA, $10 \mathrm{~mm} \mathrm{NaCl}$, and 0.5\% SDS) which was returned to the laboratory and stored at $-80{ }^{\circ} \mathrm{C}$. Dried museum tissue samples were obtained from M. L. Johnson's collection housed at the Burke Museum, University of Washington. Frozen tissue samples were obtained from the University of Alaska, Fairbanks Mammalogy collection where they were initially collected and deposited by Martin \& McComb (2002). Bone samples of P. longicaudus were obtained by identifying skeletal fragments of $P$. longicaudus in regurgitated pellets of spotted owls as part of a long-term diet study of spotted owls (Forsman et al. 2004a, b). Use of skeletal remains recovered from owl pellets as a source of DNA has previously been shown to be free of crosscontaminants from other prey consumed by owls (Taberlet \& Fumagalli 1996). We used pellets collected from two to four different owl nest sites within each $8-\mathrm{km}$ radius circle, attempting to maximize collections in space and time in case an owl foraging event included capture of multiple members of a vole family group. Spotted owls are highly territorial, have high site fidelity, and normally forage within 1-2 $\mathrm{km}$ of their nest areas during the breeding season (Forsman et al. 1984). Thus, we were sure that all of the vole specimens obtained from owl pellets came from areas near the owl nest sites that we sampled, and did not include specimens from other areas.

\section{Generation of sequence data}

DNA extraction methodology from bone and tissue samples was described in Bellinger et al. (2005). The first $400 \mathrm{bp}$ of the mitochondrial control region was amplified for each individual in our data set using the primers RTVL16000 (5'-GTCAACACCCAAAGCTGACA-3') and RtvInt1r (5'GTTGGTTTCACGGAGGATGG-3') specifically designed for this study. Polymerase chain reaction (PCR) was performed in $40-\mu \mathrm{L}$ reactions containing $50 \mathrm{~mm}$ Tris- $\mathrm{HCl} \mathrm{pH} 8.3,2.5 \mathrm{~mm}$ $\mathrm{MgCl}_{2}, 1.5 \mathrm{pmol}$ each forward and reverse primer, $500 \mu \mathrm{g} /$ $\mathrm{mL}$ bovine serum albumin (BSA), 10 units of Taq Gold (Promega), and 0.2-100 ng DNA. Each PCR run consisted of a $93{ }^{\circ} \mathrm{C}$ denaturing phase for $12 \mathrm{~min}$ followed by 40 cycles of denaturing at $93^{\circ} \mathrm{C}(30 \mathrm{~s})$, annealing at $52{ }^{\circ} \mathrm{C}(45 \mathrm{~s})$, and an extension cycle at $72{ }^{\circ} \mathrm{C}(1 \mathrm{~min})$, followed by a final extension cycle at $72{ }^{\circ} \mathrm{C}$ for $10 \mathrm{~min}$. Successful reactions were purified using Micron $30000 \mathrm{MW}$ cut-off filters (Amicon Bioseparations), after which they were bidirectionally sequenced using the primers described above. Sequencing reactions were performed with ABI BigDye chemistry run on an ABI 3100 capillary system. Following sequencer runs, all control region sequences were manually aligned using BIOEDIT version 5.0.6 (Hall 2001).

In addition to generating D-loop data, 22 specimens from eight different locations were also analysed for a 664-bp region of the cytochrome $b$ (cyt $b$ ) gene using primers and protocols described in Bellinger et al. (2005). These data were used to confirm the presence of major groups identified in D-loop analyses. Sample sizes and locations for each individual included in cyt $b$ analyses are provided in Table 1.

\section{Phylogenetic analyses}

The computer program MEGA2 (Kumar et al. 2001) was used to perform preliminary sequence analyses and derive average Jukes-Cantor genetic distances for each data set. Furthermore, we used the computer program NETWORK 
Table 1 Summary data for each sampling area depicted in Fig. 1

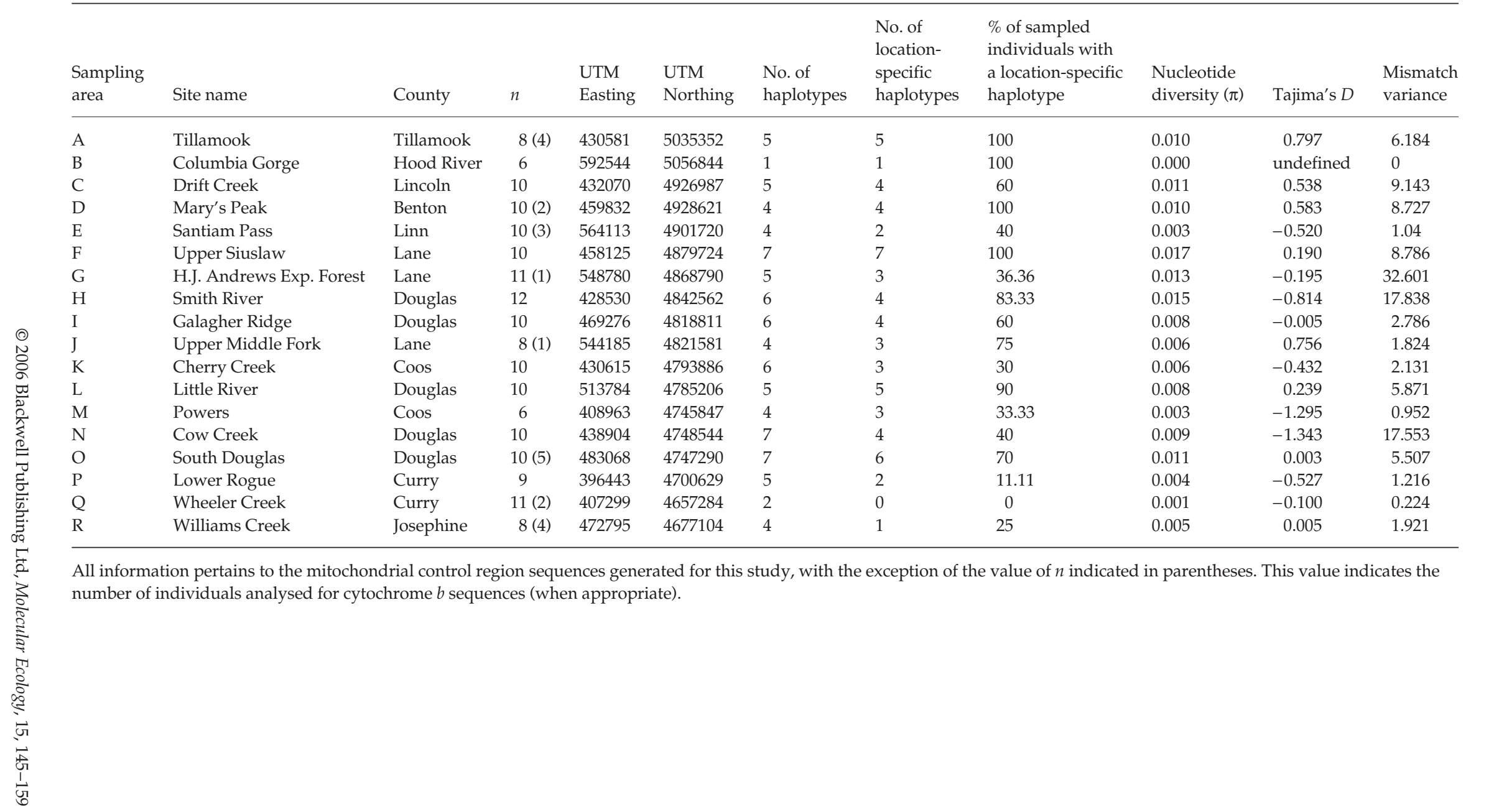


(available from www.fluxus-engineering.com) to obtain median-joining networks (Bandelt et al. 1999) of the sets of analysed haplotypes. Given the relatively large numbers of haplotypes detected in our D-loop analyses (see Results), an initial star-contraction procedure (Forster et al. 2001) with a star connection limit of 2 was used to reduce the data set to facilitate data presentation and interpretation.

\section{Population genetic analyses of mitochondrial control region sequences}

We used ARLEQUIN 2.001 (Schneider et al. 2000) to compute nucleotide diversity $(\pi)$, mismatch distributions, and Tajima's $D$ (Tajima 1989a, b) for control region haplotypes observed at each of the 18 sampling areas. The significance of $D$ values, which can potentially be used to make inferences about demographic factors such as population expansion or historical bottlenecks, was estimated through the use of 3000 replicates of a coalescent-based simulation procedure (Hudson 1990). ARLEQUIN was also used to perform an AMova (Excoffier et al. 1992) to obtain global and pairwise estimates of $F_{\mathrm{ST}}$. The significance of $F_{\mathrm{ST}}$ values was evaluated through the use of a randomization procedure based on 3000 randomization replicates.

We used two additional procedures to characterize patterns of genetic divergence of sampling areas across the range of $P$. longicaudus. First, we applied the sAmova procedure (Dupanloup et al. 2002) to identify partitions of geographically adjacent sampling areas that were maximally differentiated based on sequence data. Using the computer program SAMOVA 1.0 (http://web.unife.it/progetti/ genetica/Isabelle/samova.html), we performed analyses based on 100 simulated annealing steps and examined maximum indicators of differentiation ( $F_{\mathrm{CT}}$ values) when the program was instructed to identify $K=2$ through $K=7$ partitions of the sampling areas. Second, we employed a visualization technique to obtain a graphical representation of genetic distance patterns across the full landscape analysed in this study. We refer to the surface plots generated by this procedure as 'Genetic Landscape Shapes'. This procedure was initiated by constructing the Delaunay triangulation-based connectivity network of sampling areas and assigning genetic distances $\left(Z_{i}\right.$, calculated as the average proportion of nucleotide differences between individuals from different sampling areas) to landscape coordinates at midpoints $\left(X_{i^{\prime}} Y_{i}\right)$ of the $n$ connectivity network edges (Fig. 2). Next, we applied a simple interpolation procedure (inverse distance-weighted interpolation; Watson \& Philips 1985; Watson 1992) to infer genetic distances between locations on a uniformly spaced grid overlaid upon the entire sampled landscape (Fig. 2). Note that interpolation is commonly used in a wide variety of scientific disciplines, and no particular property of genetic data make them any less suitable for interpolation-based

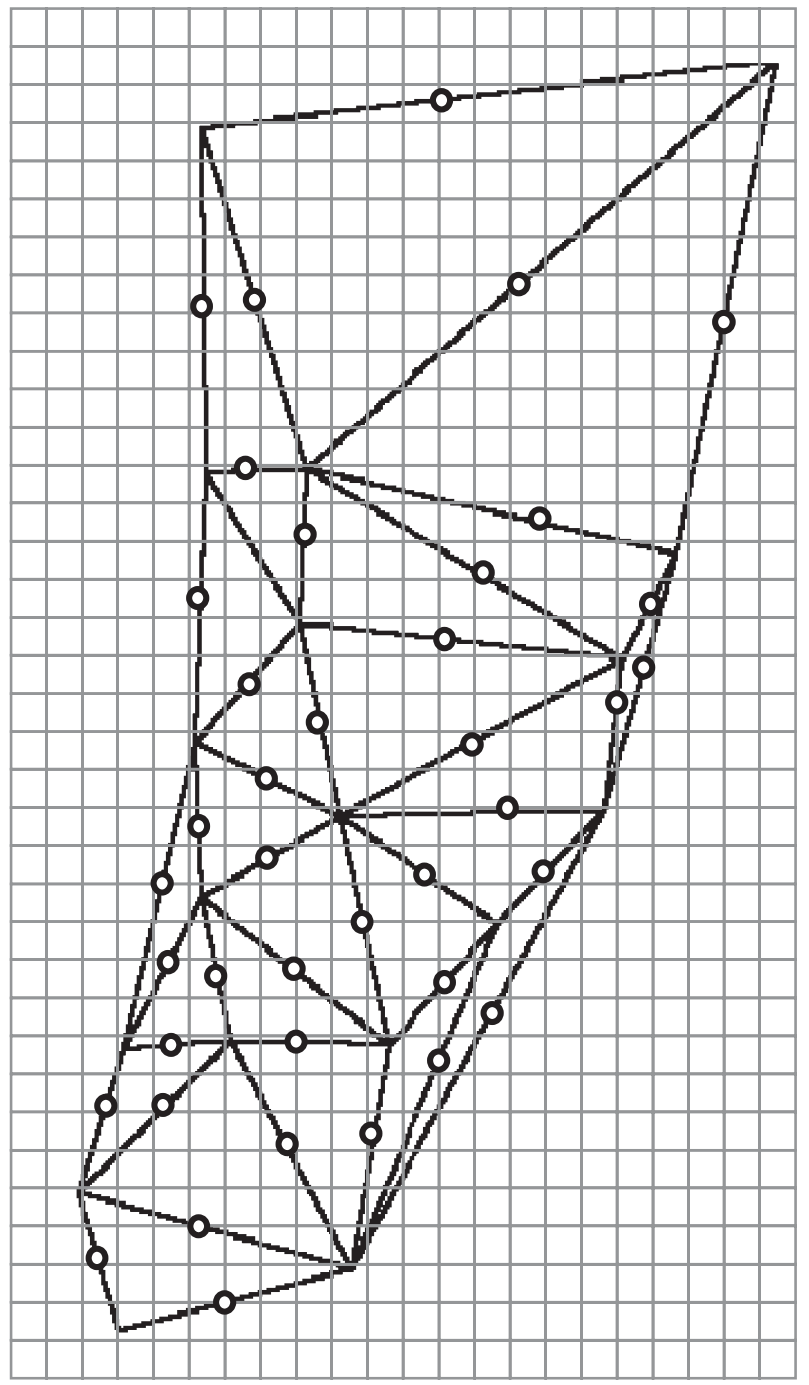

Fig. 2 Diagrammatic representation of the Delaunay triangulationbased connectivity network used for 'Genetic Landscape Shape' interpolations. Vertices of triangles on the connectivity network represent sampling areas indicated in Fig. 1 and Table 1. Small open circles at the midpoints of connectivity network edges reflect geographical locations where genetic distances between sampling areas were assigned. The rectangular grid overlaid upon the entire network indicates (symbolically in the case of this Figure) landscape coordinates where genetic distances are inferred based on the Genetic Landscape Shape interpolation procedure described in the Methods (equations 1 and 2).

analyses. For each grid coordinate $(x, y)$, we inferred a genetic distance, $z$, from each of the $i=1$ to $n$ genetic distances $\left(Z_{i}\right)$ assigned to the connectivity network as

$$
z=\frac{\sum_{i=1}^{n} w_{i} \times Z_{i}}{\sum_{i=1}^{n} w_{i}}
$$


where $w_{i}$ is a weighting function assigned to each $Z_{i}$ that is inversely proportional to the geographical distance between a grid coordinate $(x, y)$ and the actual geographical coordinates $\left(X_{i}, Y_{i}\right)$ assigned to each of the $n$ values of $Z_{i}$. More explicitly stated,

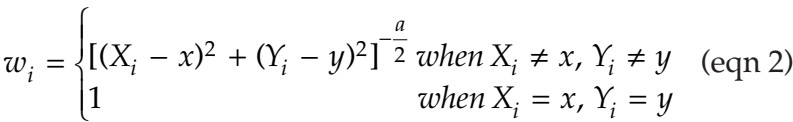

and $a$ is a distance weighting value specified for the procedure. Note that greater values of $a$ cause interpolated values to be more influenced by close points, and lower values of $a(\sim 0)$ create a tendency for all points to equally influence interpolated values. Following the interpolation procedure, we generated 3-dimensional surface plots of the sets of interpolated genetic distances where $X$ and $Y$ coordinates on the plot corresponded to geographical locations on the rectangular grid and surface plot heights (Z) reflected genetic distances. Analyses were performed using a variety of grid sizes $(20 \times 20,50 \times 50,100 \times 100)$ and with a range of distance weighting parameters $(a=0.5$ through $a=2$ ) to ensure that interpolation parameters chosen for the analysis did not overly influence interpretations of the graphical depictions generated by the procedure. Because there was substantial variation in geographical distances between sampling areas connected by the Delaunay triangulation (Fig. 2), we also followed the recommendation of Manni et al. (2004) and performed analyses using residual genetic distances derived from the linear regression of genetic vs. geographical distances. Theoretically, this approach accounted for correlation between genetic and geographical distances that was present in our data set $(r=0.577, P<$ 0.001; tested via Mantel tests) and ensured that large interpolation peaks were not resolved by the procedure solely due to the fact that one or a few sampling areas were geographically isolated.

Analyses described above, particularly our Genetic Landscape Shape interpolations, suggested distinct patterns of genetic structure and variation along a North/South axis (see Results). To formally characterize these patterns, we performed a series of post hoc linear regressions (and in some cases second-order polynomial regressions) using UTM Northing as the independent variable and variables such as Tajima's $D$, nucleotide diversity, and the percentage of sampled individuals from an area bearing a locationspecific haplotype as response variables. Comparable analyses were performed using pairwise genetic distances (average between-location interindividual genetic distances) and residual genetic distances obtained from the linear regression of genetic distance on geographical distances. In these analyses, genetic distances (or residual genetic distances) were regressed against midpoint UTM Northing values between pairs of sampling areas. Genetic distancebased analyses were performed using all pairwise genetic distances, with congruent analyses performed using only the subset of genetic distances used for Genetic Landscape Shape interpolations (Fig. 2). Because frequency distributions of many of the statistics described above are unknown, and because genetic distances between sites were nonindependent, randomization-based statistical procedures (using 5000 randomization replicates) were used to evaluate $P$ values for both the linear and second-order polynomial regressions described above. For linear regression analyses, the significance of each observed $R^{2}$ value was obtained by randomly shuffling elements of the vector of $x$-axis values and recording the proportion of randomization replicates where random $R^{2}$ values were greater than or equal to the observed $R^{2}$ value (thus serving as a $P$ value surrogate). For second order polynomial regressions, data were initially analysed using Excel 2000 (Microsoft, Inc.) to obtain regression equations and $R^{2}$ values. Next, we used the sum of squared deviations (SSD) of observed $Y$ values from equationpredicted $Y$ values as a surrogate value describing the fit of observed data to the regression model (an $R^{2}$ surrogate). $P$ values were estimated for the regression equation via randomization as described above and recording the proportion of randomization replicates where random SSD were less than or equal to observed SSD.

\section{Results}

\section{Phylogenetic analyses}

Analysis of the first 400 nucleotides of the D-loop revealed 70 unique haplotypes (GenBank Accession nos AY836255AY836324; 46 polymorphic sites; Appendix) among the 169 Phenacomys longicaudus individuals sequenced. Average Jukes-Cantor genetic distances among haplotypes were relatively small (mean $=0.021$, range: $0.003-0.041)$. Sequence analyses of $22 P$. longicaudus specimens for a 664-bp region of the cyt $b$ gene revealed 14 haplotypes (29 polymorphic sites; Appendix) with an average Jukes-Cantor genetic distance of 0.011 (range: 0.002-0.020).

Results of the median-joining network analysis of both genes suggested the presence of a general nonrandom association of haplotypes based on geography (Fig. 3). We detected a group of haplotypes observed in northern sampling areas, while a separate group of haplotypes from southern sampling areas was also observed. The mismatch distribution for the set of $P$. longicaudus control region haplotypes was distinctly bimodal, and also suggested the presence of two separate lineages (Fig. 3A). Based on our D-loop data, the average nucleotide diversity from the northern haplotype group $(\pi=0.017, \mathrm{SE}=0.004)$ was comparable to that seen among haplotypes from the southern group $(\pi=0.012, \mathrm{SE}=0.003)$. Similar patterns were also seen for the cyt $b$ data indicating identical levels of nucleotide diversity in northern vs. southern groups (both groups 
A

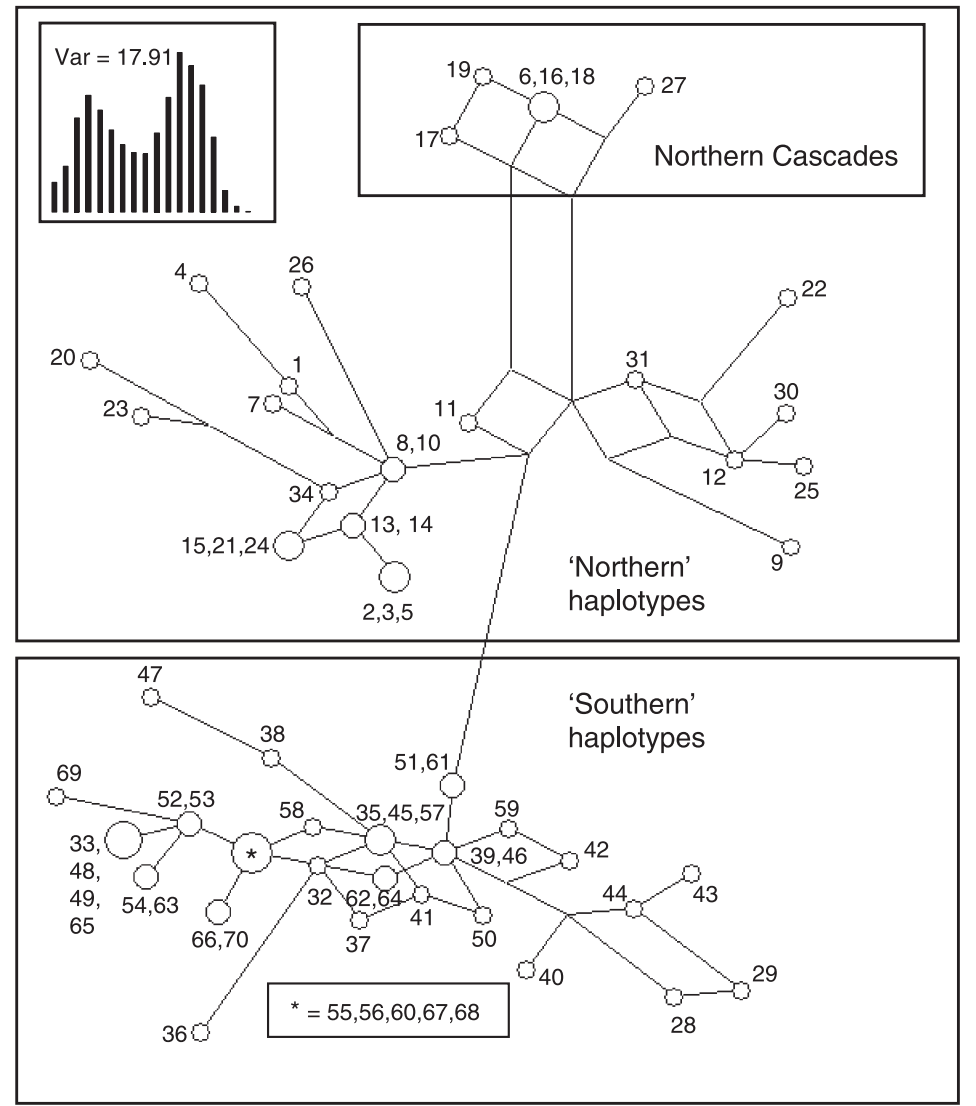

B

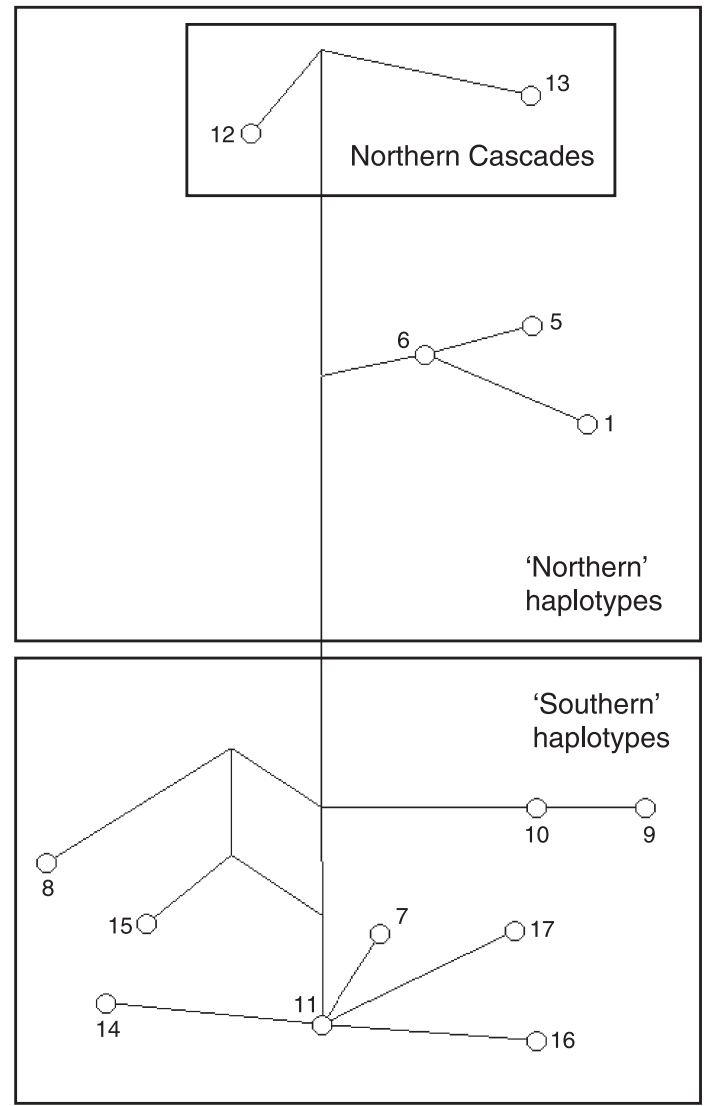

Fig. 3 Median-joining networks of (A) D-loop and (B) cytochrome $b$ haplotypes detected in this study. Numbers adjacent to open circles (network nodes) refer to haplotypes listed in Appendix. D-loop data are presented using an initial star contraction procedure with a maximum star radius of 2. Panel A inset illustrates the bimodal mismatch distribution and variance of D-loop haplotypes (X-axis reflects number of nucleotide differences, $Y$-axis reflects frequency). See Appendix for information on geographic locations where each haplotype was detected.

produced identical results: $\pi=0.007, \mathrm{SE}=0.002)$. Among 'Northern' haplotypes, our network analyses of both genes further indicated that there was also additional subdivision of alleles into 'Northern Cascade range' and 'Northern Coast range' sequences (Figs 1 and 3).

\section{Population genetic analyses}

Fifty-eight of the 70 unique control region haplotypes detected in this study were observed in a single sampling area (Appendix). Geographical distributions of haplotypes found in more than one sampling area were restricted to closely situated locations with one notable exception: four copies of haplotype 7 were observed in area C, while a single instance of that haplotype was detected in area $\mathrm{N}$ (Appendix). Estimates of genetic (nucleotide) diversity varied considerably among sampling areas, ranging from zero to $\pi=0.0166$ (Table 1 ). Although no values of Tajima's $D$ were significantly different than zero $(P>0.05)$, values were also highly variable among sampling areas (Table 1). As with other location-specific statistics that were calculated, mismatch variances were highly variable for each sampling area (Table 1).

Results of our AMOVA indicated the presence of substantial genetic structure within $P$. longicaudus. The overall $F_{\mathrm{ST}}$ value was $0.607(P<0.001)$, and pairwise sampling area estimates of $F_{\mathrm{ST}}$ ranged from $\sim 0.03$ to $\sim 0.97$. One hundred twenty of the 153 pairwise $F_{\mathrm{ST}}$ values were significantly different than 0 following evaluation of $P$ values using sequential Bonferroni corrections. Furthermore, our SAMOVA analyses clearly indicated that there were distinct groups of genetically defined sampling areas. In analyses where $K=2$, partitions of sampling areas were identified that suggested northern vs. southern groups (partitions: ABCDEFG vs. HIJKLMNOPQR; $F_{\mathrm{CT}}=0.471$ ). In analyses where $K=3$, an additional partition was identified that subdivided northern sampling areas into distinct eastern and western groups (partitions: ACDF vs. BEG vs. 


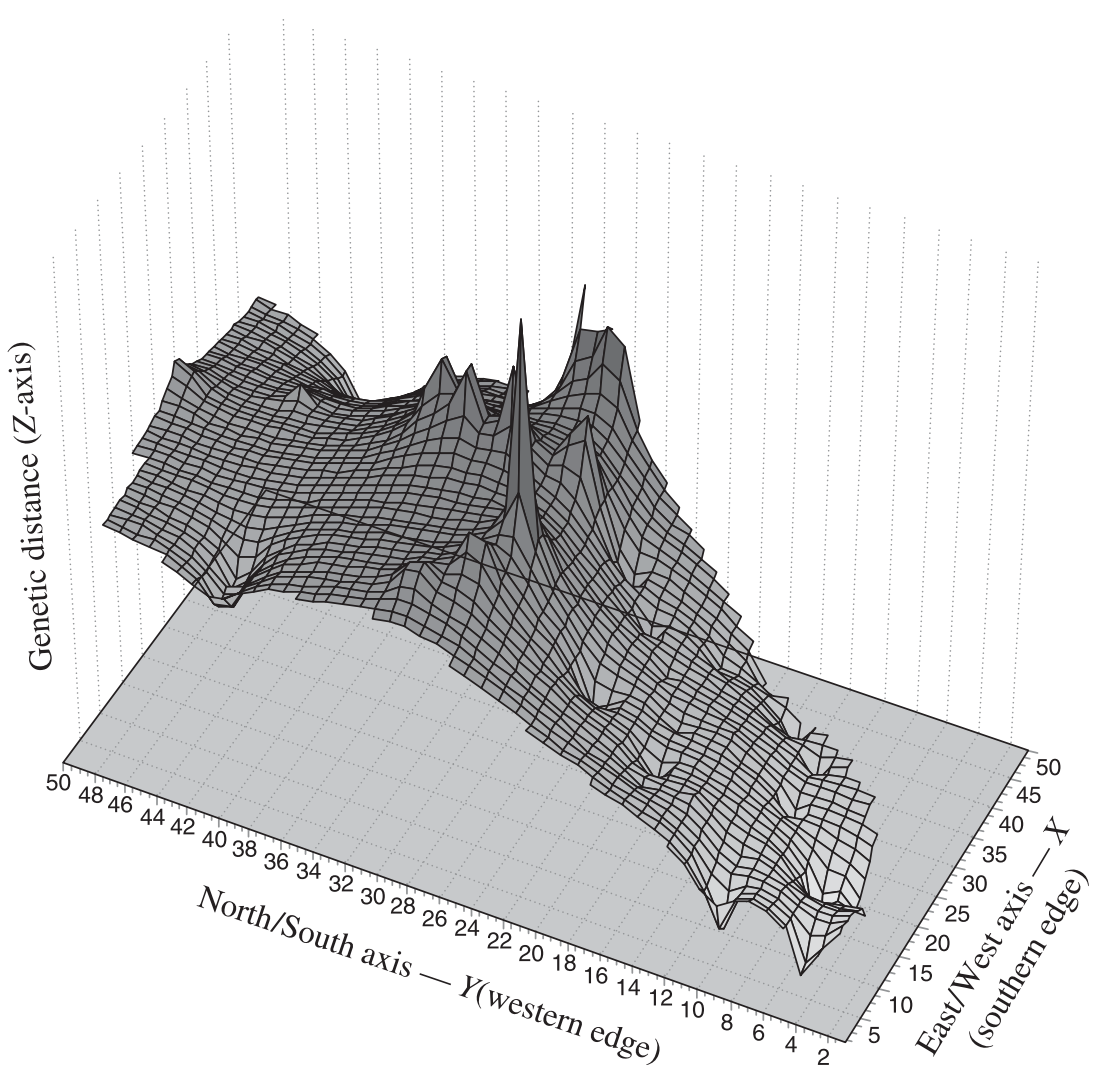

Fig. 4 Results of a Genetic Landscape Shape interpolation analysis using a $50 \times 50$ grid and a distance weighting parameter $(a)$ of 1. $X$ and $Y$ axes correspond to geographic locations within the overall physical landscape examined in this study (Fig. 1). Surface plot heights reflect genetic distances. Qualitatively similar results were obtained using different grid sizes and a range of distance weighting parameters $(a=0.5-2)$.
HIJKLMNOPQR; $\left.F_{\mathrm{CT}}=0.571\right)$. We note that the indicator of differentiation used for this analysis $\left(F_{\mathrm{CT}}\right)$ was greatest for the $K=3$ case, and that $F_{\mathrm{CT}}$ values gradually decreased relative to the maximum value in the $K=4$ through $K=7$ analyses. Thus, our analysis suggested the presence of three groups of maximally differentiated sampling areas.

Overall, our Genetic Landscape Shape interpolation analysis produced surface plots that qualitatively supported results from SAMOVA analyses (Fig. 4). A 'ridge' (indicating greatest genetic distances) was observed in an East/West orientation at the midpoint of $P$. longicaudus' range while an additional smaller ridge ran directly North from the main discontinuity. Qualitatively similar depictions were also observed regardless of the rectangular grid size or distance weighting parameter chosen for analyses (results not shown). Likewise, use of raw genetic distances or residual genetic distances did not have any appreciable effect on analysis outcomes. Interestingly, unlike sAMOvA analyses, our surface plots illustrated additional features of the 'Landscape Shape' beyond identification of sets of maximally differentiated sampling locations. Specifically, in areas to the south of the main genetic discontinuity, our analysis indicated that patterns of genetic distances decreased with decreasing latitude (Fig. 4).

Our randomization-based regression analyses revealed multiple distinct latitudinal trends. For example, values of
Tajima's $D$ were positively associated with increasing latitude $\left(R^{2}=0.235, P=0.022\right)$, as was the percentage of individuals from a sampling area bearing a locationspecific haplotype $\left(R^{2}=0.531, P<0.001\right)$. Interestingly, patterns of nucleotide diversity best fit a second-order polynomial regression from south to north $\left(R^{2}=0.387\right.$, $P=0.003$; Fig. 5A). In genetic distance-based regressions, all analyses showed significant linear increases in genetic distances with increasing latitude, although second-order polynomial curves clearly provided much better fits to the data (Fig. 5B). This pattern held consistently not only when all pairwise genetic distances were used in analyses (Linear $R^{2}=0.219, P<0.001$; Polynomial $R^{2}=0.455, P<0.001$ ), but also when (i) all pairwise residual genetic distances were used (Linear $R^{2}=0.107, P<0.001$; Polynomial $R^{2}=$ $0.355, P<0.001$ ), (ii) raw genetic distances from the subset of contrasts used for interpolation (Fig. 2) were analysed (Linear $R^{2}=0.297, P=0.004$; Polynomial $R^{2}=0.421, P<$ 0.001 ), and when residual genetic distances from the subset of contrasts used for interpolation were analysed (Linear $R^{2}=0.176, P=0.003 ;$ Polynomial $R^{2}=0.436, P<0.001$ ).

\section{Discussion}

Our sampling of both individuals and 'sampling areas' permitted us to resolve patterns of genetic structure 


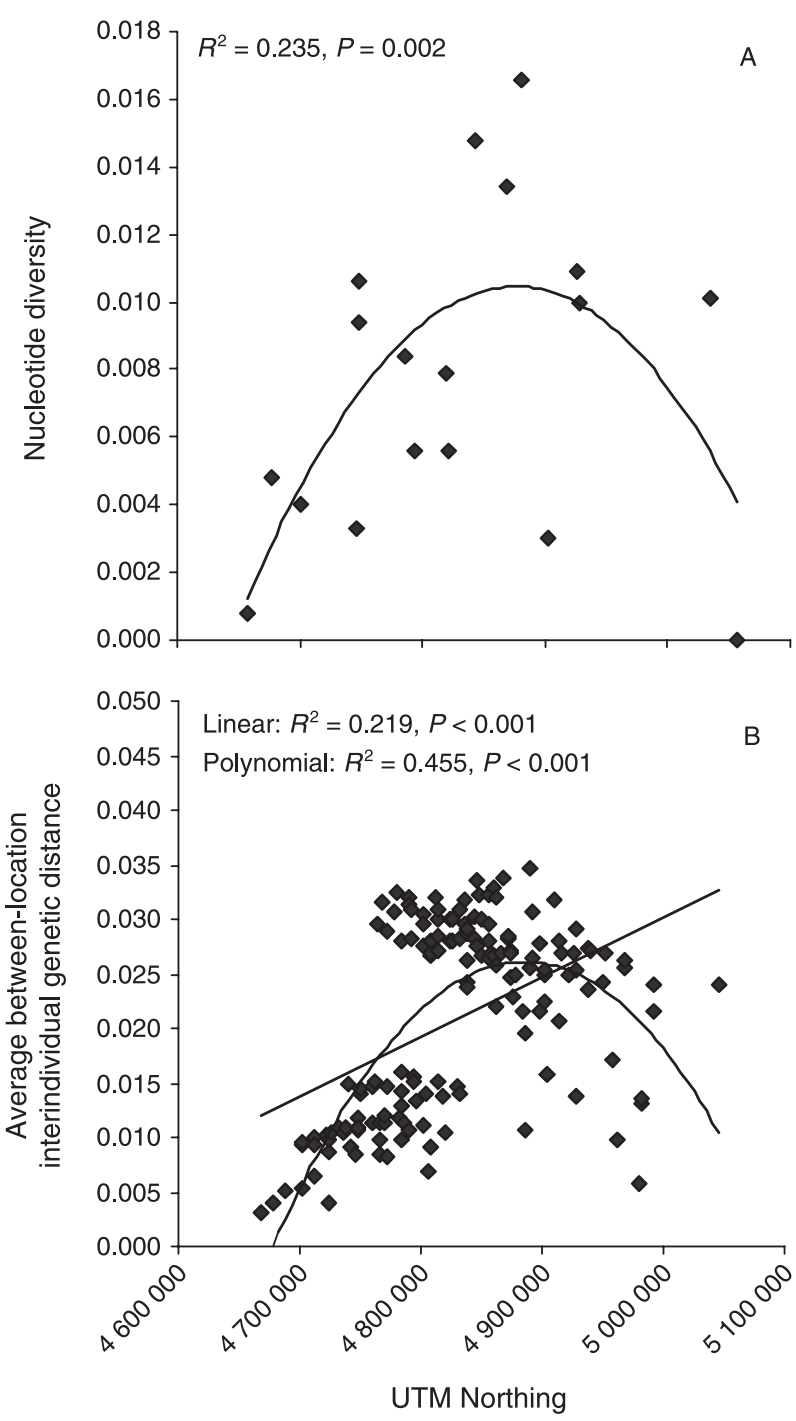

Fig. 5 Results of second-order polynomial regression analyses performed along a south-north transect for this study. (A) Nucleotide diversity was generally highest in mid-range sites. (B) Results of regression analyses performed on genetic distance data. Genetic distances were plotted at the midpoint UTM Northing coordinate between pairs of contrasted sampling areas. Panel B illustrates results when all raw pairwise genetic distances were analysed. Comparable results were obtained when all pairwise residual genetic distances were used, when raw genetic distances from the subset of contrasts used for interpolation (Fig. 2) were analysed, and when residual genetic distances from the subset of contrasts used for interpolation were analysed (See Results). In contrast to the analyses described above, Tajima's $D$ and the percent of sampled individuals from a location with a locationspecific haplotype showed significant positive associations with increasing latitude. See Results for more information.

and diversity across the range of Phenacomys longicaudus that suggested the influence of historical climate change, vicariance, and habitat connectivity. Of primary importance was the detection of two putative 'discontinuities' within the species' range. We discuss these patterns and their likely causes in more detail below.

\section{The North/South 'discontinuity'}

Our phylogenetic analyses indicated generalized support for the presence of a group of northern haplotypes that were distinct from those detected among southern locations (Fig. 3). Overall, our analysis of $P$. longicaudus mitochondrial genetic variation appears to produce results that are superficially comparable to intraspecific genetic patterns observed in many other Cascade/Sierran distributed taxa (see Soltis et al. 1997 for a review of plant data; see Brunsfeld et al. 2001 for additional reviews of both plant and animal data; note that $P$. longicaudus inhabits a very small subset of the geographical range inhabited by the majority of Cascade/ Sierran plant and animal species historically analysed from the region). In particular, chloroplast DNA (cpDNA) analyses of Alnus rubra (Strenge 1994; Soltis et al. 1997) and Ribes bracteosum (Soltis et al. 1997) have demonstrated patterns of genetic divergence at nearly the same location where strong mitochondrial genetic structure occurs in P. longicudus (Fig. 4). The perennial herb Tolmiea menziesii also demonstrates a particularly striking pattern at this location, as it corresponds to not only an area of cpDNA divergence, but also a transition from diploid individuals in the southern area of the species' range to tetraploid individuals in northern areas (Soltis et al. 1989).

Our population genetic analyses suggested the presence of extremely strong structure $\left(F_{\mathrm{ST}}=0.607\right)$ and highly variable pairwise $F_{\mathrm{ST}}$ values ranging from $\sim 0.03$ to 0.97 . However, our spatial genetic analyses (sAmova; Genetic Landscape Shape interpolations, Fig. 4) permitted us to understand the heterogeneity of these patterns across the sampled landscape. Most important were results illustrating that greatest genetic distances occur in $P$. longicaudus in an East/West direction close to the midpoint of this species' range (Fig. 4; SAMOVA results). Regression analyses along a North/South transect reflected this same pattern (Fig. 5B) by showing that genetic distances were greatest among mid-range sampling areas. A complete understanding of this major pattern in P. longicaudus is best obtained from close examination of within-location genetic diversity patterns and location-specific mismatch variances. In regression analyses of nucleotide diversity along a North/South transect, within-location diversity was greatest for mid-range sampling areas (Fig. 5A; Table 1). Furthermore, based on patterns observed in location-specific mismatch variances (Table 1), our analyses also revealed that mismatch distribution variances were greatest in mid-range areas $G$ and $\mathrm{H}$. Overall, this pattern suggests that these areas effectively contain large subsets of the total genetic variation within P. longicaudus. To illustrate, of the 11 individuals analysed from area G, 9 contained haplotypes found in 
the lineage of sequences that were unique to the northern Cascade region while the remaining two haplotypes were more closely allied with other southern sequences (Fig. 3; Appendix). Likewise, of the 12 individuals sequenced from area $\mathrm{H}, 5$ contained haplotypes that evolved within the northern lineage while the remaining 7 were apparently of southern descent (Fig. 3; Appendix). Based on this pattern, it is quite clear that large genetic distances found in the region are not due the presence of a strict discontinuity or overt geographical barrier, per se. Instead, our pattern reflects the fact that locations $\mathrm{G}$ and $\mathrm{H}$ contain divergent haplotypes, while locations to the north or south of these areas contain sets of relatively closely related haplotypes.

Thus, our data presumably allow us to distinguish between the North-South recolonization hypothesis and the Leading Edge hypothesis of Soltis et al. (1997). In the case of P. longicaudus, a pattern where haplotypes from different lineages are present within sampling areas at least superficially resembles scenarios where secondary contact has occurred (the North-South recolonization hypothesis) and that separate historical northern and southern refugia may have played important roles in shaping contemporary patterns of genetic structure in this species (but see additional discussion below). This pattern is also typified by data from location $\mathrm{N}$, where a single instance of northern haplotype 7 was detected (Appendix). Given that haplotype 7 is closely related to other northern haplotypes (Fig. 3) and is also found in relatively high frequency at area C (Appendix), we suggest that this observation may reflect the southernmost extent of introgression of northern alleles into more southern regions.

In formulating the 'Leading Edge' and 'North-South recolonization' hypotheses, Soltis et al. (1997) suggested that genetic diversity may be reduced among individuals from northern regions (see Introduction). However, our analyses revealed that nucleotide diversity was generally comparable for both northern and southern haplotypes groups (see Results). Based on this inference, our data clearly suggest that a northern range expansion has not recently occurred. Furthermore, this result also suggests that rangewide phylogenetic diversity of the northern haplotype group was not recently reduced by glacial processes that isolated individuals into distinct refugia. Current data suggest that the Cordilleran ice sheet from the Wisconsin glacier (glacial maximum 12 000 years ago) did not spread southward far enough to cover the geographical region that $P$. longicaudus now inhabits (Andersen \& Borns 1994; Bonnicksen 2000). It is unknown if this species previously had a more extensive historical northern distribution prior to the most recent glacial advance. However, climate change associated with the Wisconsin glaciation may have had dramatic effects on forest communities of the Cascade and Coast Range mountains. Although much of the northern mountain regions currently contain vast forests of Douglas fir, western hemlock, and Sitka spruce (which are the primary food sources for P. longicaudus; Verts \& Carraway 1998), these forests became fragmented during the Wisconsin glaciation by tundra and cold steppes, with even Douglas fir forests in the Klamath region of northern California seeing at least modest reductions in size (Bonnicksen 2000). Thus, if we assume that $P$. longicaudus inhabited the northern region of its range prior to the Wisconsin glaciation, two lines of evidence suggest that this species may have been influenced by climate change-induced habitat fragmentation during the Wisconsin glaciation.

First, although no individual value of Tajima's $D$ was significantly different from random expectations, our analyses showed a significant positive association between this statistic and latitude $\left(R^{2}=0.235, P=0.022\right)$. Factors such as population structure and selection can influence $D$ (Charlesworth et al. 1993; Wall 1999; Kreitman 2000; Ptak \& Przeworski 2002), however, this statistic is also frequently used to make inferences about demographic processes within species (Matocq 2002; Mahoney 2004). Simulation analyses have shown that values of $D$ take on negative values in populations that have undergone demographic expansions, while positive $D$ values are transiently observed in populations after incomplete bottlenecks (Tajima 1989b). Thus, our results are consistent, at least in concept, with patterns that may have been produced if northern $P$. longicaudus populations experienced bottlenecks attributable to historical climate change-induced forest fragmentation. Second, our regression analyses also showed that northern sampling areas were much more likely to contain locationspecific haplotypes $\left(R^{2}=0.531, P<0.001\right)$. Accordingly, variation in the extent of forest fragmentation in northern vs. southern areas likely produced patterns where gene flow was more substantially reduced in northern regions. This general conclusion is also consistent with results from our Genetic Landscape Shape interpolations (Fig. 4) and regression analyses (Fig. 5B). These analyses showed strong tendencies for genetic distances between sampling areas to decrease monotonically with decreasing latitude in the southern half of $P$. longicaudus' range. Overall, they may reflect the presence of less fragmented habitat in southern regions during periods of climate change associated with the Wisconsin glaciation.

Based on these inferences, we suggest that our data bear conceptual relationships to patterns emphasized by Demboski \& Cook (2001), Nielson et al. (2001), and Wilke \& Duncan (2004), who recognized that phylogeographical patterns may be present within species that correspond to both 'shallow' (recent processes) and 'deep' (older processes) divergence. In the case of $P$. longicaudus, we suggest that the overt pattern revealed by the presence of separate northern and southern haplotype groups reflects processes that may be attributable to older (and perhaps more 
extensive) glaciation events during the Pleistocene. In contrast, the more recent Wisconsin glacier may have instead worked to produce patterns that bore the signature of habitat fragmentation that was also revealed by our analyses. Given that our analyses revealed a major North/South pattern that was directly comparable to that observed in many plant species, we suggest that it may also be useful to perform more detailed analyses of these taxa over the relatively small geographical region examined in this study to determine if they also bear the signature of more recent habitat fragmentation observed in $P$. longicaudus. Such investigations would also be appropriate for the plants used as primary food sources by P. longicaudus (Douglas fir, western hemlock, and Sitka spruce), as our analysis interpretations also required us to invoke arguments of habitat fragmentation related to these other dominant plant species from the region (see above).

\section{The East/West discontinuity}

In addition to the major pattern in the data set, where the greatest genetic distances were observed in an area that subdivided northern and southern sampling locations, our analyses also detected a secondary delineation that subdivided eastern and western regions of the northern sampling areas (Fig. 4; SAMOVA results). Interestingly, while the primary North/South subdivision did not involve a strict discontinuity or overt phylogeographical barrier, the secondary subdivision likely corresponds to the separation of the Cascade mountain range from the Coast Ranges by the Willamette Valley (Fig. 1). Substantial geological evidence exists for the presence of sizeable historical floods in the region since the late Pleistocene (Baldwin 1976; Bishop 2003). Following the Illinoian glaciation ( 250000 years ago), the Willamette Valley was completely filled with water and accumulated new sediments up to $\sim 30 \mathrm{~m}$ thick (Franklin \& Dyrness 1988). An additional flood, due to the presence of an ice dam along the Columbia River near the end of the Wisconsin glaciation (10 000-15 000 years ago), effectively re-routed the river and deluged the valley with water and silts that reached elevations upwards of $122 \mathrm{~m}$ (Franklin \& Dyrness 1988). Currently, coniferous forest habitats occupied by $P$. longicaudus are mainly restricted to mountainous regions in the Klamath, Cascades, and Coast Range Provinces (Verts \& Carraway 1998). In contrast, the Willamette Valley, which separates the Coast Ranges and Cascades Mountains, is now covered primarily by farmlands, grasslands and oak (Quercus) woodlands (Franklin \& Dyrness 1988; Taft \& Haig 2003) that do not provide habitat for tree voles. Thus, combined evidence of historical processes, contemporary habitat variation, and genetic data suggest that gene flow between regions has been minimal.

We are unaware of any other study emphasizing the importance of the Willamette Valley as a phylogeographical barrier within species, although genetic analyses of the pocket gopher Thomomys bulbivorous (a Willamette Valley endemic species) suggested that this taxon was influenced by the extensive historical flooding of the region (Carraway \& Kennedy 1993). Our detection of a pattern of divergence between $P$. longicaudus sampling areas on either side of the valley may be attributable to the fact that (i) we employed what might be considered only modest levels of sampling to (ii) a species that inhabits a relatively small geographical range. Most other phylogeographic analyses of the northwestern United States generally incorporate samples from species occupying substantially larger geographical regions than that inhabited by P. longicaudus (typified by, but not limited to, Conroy \& Cook 2000; Demboski \& Cook 2001; Zheng et al. 2003; Kuchta \& Tan 2005). As such, the Willamette Valley 'barrier' may not have been previously identified due to insufficient sampling on either side of the valley (in an attempt by researchers to maximize the spatial extent of sampling). Alternatively, if this East-West discontinuity is relatively recent (perhaps due to recent Pleistocene flooding of the Willamette Valley; see above), then structure may have been obscured or undetectable in contrast to other more overt patterns revealed over the large spatial scales examined (see Discussion of 'deep' vs. 'shallow' divergence above). To address this issue, we suggest that researchers may need to employ more fine-scaled spatial sampling to ultimately detect (and understand) important recent evolutionary and phylogeographical determinants of genetic structure over landscapes.

\section{Conclusions}

Our analysis of genetic variation across the full range of Phenacomys longicaudus permitted us to not only understand phylogeographic patterns within this species, but also to place our inferences in the context of the emerging body of literature from the Pacific Northwestern region of North America dealing with genealogical concordance among species. Given patterns observed in P. longicaudus, we suggest that future work based on analyses of other western Phenacomys species could also prove valuable. For example, Phenacomys albipes is primarily distributed in western Oregon from Washington to northern California (Verts \& Carraway 1998) and may show similar patterns to those observed in this study for $P$. longicaudus. Furthermore, Phenacomys pomo is found in the northern Sierra mountains of California (south of $P$. longicaudus' range), while $P$. intermedius is broadly distributed in areas including eastern regions of the Cascade Range in Oregon, the intermountain western areas of the United States, and large expanses of continental Canada (Verts \& Carraway 1998). Future work on Phenacomys, particularly in the form of detailed multispecies analyses (e.g. Zheng et al. 2003; Mahoney 2004; Steele et al. 2005), may not only provide exceptional 
opportunities to document genealogical concordance in Oregon (in the case of $P$. longicaudus and P. albipes), but also allow us to develop a better understanding of historical processes and events that lead to speciation among northwestern Phenacomys taxa over temporal and spatial scales greater than that involved in our current study.

\section{References}

Andersen BG, Borns HW Jr (1994) The Ice Age World: An Introduction to Quaternary History and Research with Emphasis on North America and Northern Europe During the Last 2.5 Million Years. Scandinavian University Press, Copenhagen.

Baldwin EM (1976) Geology of Oregon, 3rd edn. Kendall/Hunt Publishing, Toronto.

Bandelt H-J, Forster P, Röhl A (1999) Median-joining networks for inferring intraspecific phylogenies. Molecular Biology and Evolution, 16, 37-48.

Bellinger MR, Haig SM, Forsman ED, Mullins TD (2005) Taxonomic relationships among Phenacomys voles as inferred by cytochrome b. Journal of Mammalogy, 86, 201-210.

Bishop EB (2003) In Search of Ancient Oregon. Timber Press, Portland, Oregon.

Bonnicksen TM (2000) America's Ancient Forests: from the Ice Age to the Age of Discovery. John Wiley \& Sons, New York.

Brunsfeld SJ, Sullivan J, Soltis DE, Soltis PS (2001) Comparative phylogeography of northwestern North America: a synthesis. In: Integrating Ecology and Evolution in a Spatial Context (eds Silvertown J, Antonovics J), pp. 319-339. Blackwell Science Ltd, Oxford.

Bury RB, Perl CA (1999) Klamath-Siskiyou herpetofauna: biogeographic patterns and conservation strategies. Natural Areas Journal, 19, 341-350.

Carey AB (1989) Wildlife associated with old-growth forests in the Pacific Northwest. Natural Areas Journal, 9, 151-162.

Carraway LN, Kennedy PK (1993) Genetic variation in Thomomys bulbivorous, an endemic to the Willamette Valley, Oregon. Journal of Mammalogy, 74, 952-962.

Charlesworth B, Morgan MT, Charlesworth D (1993) The effects of deleterious mutations on neutral molecular variation. Genetics, 134, 1289-1303.

Conroy CJ, Cook JA (2000) Phylogeography of a post-glacial colonizer: Microtus longicaudus (Rodentia: Muridae). Molecular Ecology, 9, 165-175.

DellaSala DA, Reid SB, Frest TJ, Strittholt JR, Olson DM (1999) A global perspective on the biodiversity of the Klamath-Siskiyou Ecoregion. Natural Areas Journal, 19, 300-319.

Demboski JR, Cook JA (2001) Phylogeography of the dusky shrew, Sorex monticolus (Insectivora, Soricidae): insight into deep and shallow history in northwestern North America. Molecular Eco$\log y, 10,1227-1240$.

Demboski JR, Sullivan J (2003) Extensive mtDNA variation within the yellow-pine chipmunk, Tamis amoenus (Rodentia: Sciuridae), and phylogeographic inferences from northwest North America. Molecular Phylogenetics and Evolution, 26, 389-408.

Dupanloup I, Schneider S, Excoffier L (2002) A simulated annealing approach to define the genetic structure of populations. Molecular Ecology, 11, 2571-2581.

Excoffier L, Smouse P, Quattro JM (1992) Analysis of molecular variance inferred from metric distances among DNA haplotypes: application to human mitochondrial DNA restriction data. Genetics, 131, 479-491.

Forsman ED, Anthony RG, Zabel CJ (2004a) Distribution and abundance of red tree voles in Oregon based on occurrence in pellets of northern spotted owls. Northwest Science, 78, 294-302.

Forsman ED, Anthony RG, Zabel CJ (2004b) Diets and foraging behavior of northern spotted owls in Oregon. Journal of Raptor Research, 38, 214-230.

Forsman ED, Meslow EC, Wight HM (1984) Distribution and biology of the spotted owl in Oregon. Wildlife Monographs, 87, 1-64.

Forster P, Torroni A, Renfrew C, Röhl A (2001) Phylogenetic star contraction applied to Asian and Papuan mtDNA evolution. Molecular Biology and Evolution, 18, 1864-1881.

Franklin JF, Dyrness CT (1988) Natural Vegetation of Oregon and Washington. Oregon State University Press, Corvallis, Oregon.

Hall ER (1981) The Mammals of North America, 2nd edn. John Wiley \& Sons, New York.

Hall T (2001) BIOEDIT. North Carolina State University, Raleigh, North Carolina. Computer software available from www.mbio.ncsu.edu/BioEdit/bioedit.html.

Howell AB (1926) Voles of the genus Phenacomys. North American Fauna, 48, 1-66.

Hudson RR (1990) Gene genealogies and the coalescent process. In: Oxford Surveys in Evolutionary Biology (eds Futuyama D, Antonovics JD), pp. 1-44. Oxford University Press, New York.

Huff MH, Holthausen RS, Aubry KB (1992) Habitat management for red tree voles in Douglas-fir forests. United States Department of Agriculture, Forest Service General Technical Report, PNWGTR-302: 1-16.

Irwin DE (2002) Phylogeographic breaks without geographic barriers to gene flow. Evolution, 56, 2383-2394.

Johnson ML (1968) Application of blood protein electrophoretic studies to problems in mammalian taxonomy. Systematic Zoology, 17, 23-30.

Kreitman M (2000) Methods to detect selection in populations with applications to the human. Annual Review of Genomics and Human Genetics, 1, 539-559.

Kuchta SR, Tan A-M (2005) Isolation by distance and post-glacial range expansion in the rough-skinned newt, Taricha granulose. Molecular Ecology, 14, 225-244.

Kumar S, Tamura K, Jakobsen IB, Nei M (2001) MEGA2: molecular evolutionary genetics analysis software. Bioinformatics, 17, 1244-1245.

Mahoney ML (2004) Molecular systematics and phylogeography of the Plethodon elongates species group: combining phylogenetic and population genetic methods to investigate species history. Molecular Ecology, 13, 149-166.

Manni F, Guerard E, Heyer E (2004) Geographic patterns of (genetic, morphologic, linguistic) variation: how barriers can be detected by using Monmonier's algorithm. Human Biology, 76, 173-190.

Martin KJ, McComb WC (2002) Small mammal habitat associations at patch and landscape scales in Oregon. Forest Science, 48, 255-264.

Maser C, Mate BR, Franklin JF, Dyrness CT (1981) Natural history of Oregon coast mammals. USDA Forest Service, General Technical Report PNW-133.

Matocq MD (2002) Phylogeographical structure and regional history of the dusky-footed woodrat, Neotoma fuscipes. Molecular Ecology, 11, 229-242.

Monsen KJ, Blouin MS (2003) Genetic structure in a montane ranid frog: restricted gene flow and nuclear-mitochondrial discordance. Molecular Ecology, 12, 3275-3286. 
Nielson M, Lohman K, Sullivan J (2001) Phylogeography of the tailed frog (Ascaphus truei): implications for the biogeography of the Pacific Northwest. Evolution, 55, 147-160.

Pfrender MP, Hicks J, Lynch M (2004) Biogeographic patterns and current distribution of molecular-genetic variation among populations of speckled dace, Rhinichthys osculus (Girard). Molecular Phylogenetics and Evolution, 30, 490-502.

Ptak SE, Przeworski M (2002) Evidence for population growth in humans is confounded by fine-scale population structure. Trends in Genetics, 18, 559-563.

Schneider S, Roessli D, Excoffier L (2000) ARLEQUIN (version 2.001): A software for population genetics data analysis. Genetics and Biometry Laboratory, Department of Anthropology, University of Geneva, Switzerland.

Soltis DE, Gitzendanner MA, Strenge DD, Soltis PE (1997) Chloroplast DNA intraspecific phylogeography of plants from the Pacific Northwest of North America. Plant Systematics and Evolution, 206, 353-373.

Soltis DE, Soltis PS, Ranker TA, Ness BD (1989) Chloroplast DNA variation in a wild plant, Tolmiea menziessi. Genetics, 121, 819-826.

Steele CA, Carstens BC, Storfer A, Sullivan J (2005) Testing hypotheses of speciation timing in Dicamptodon copei and Dicamptodon aterrimus (Caudata: Dicamptodontidae). Molecular Phylogenetics and Evolution, 36, 90-100.

Strenge D (1994) The intraspecific phylogeography of Polystichum munitum and Alnus rubra. MS Thesis, Washington State University.

Taberlet P, Fumagalli L (1996) Owl pellets as a source of DNA for genetic studies of small mammals. Molecular Ecology, 5, 301305.

Taft OW, Haig SM (2003) Historical wetlands in Oregon's Willamette Valley: implications for restoration of winter waterbird habitat. Wetlands, 23, 51-64.

Tajima F (1989a) Statistical method for testing the neutral mutation hypothesis. Genetics, 123, 585-595.

Tajima F (1989b) The effects of change in population size on DNA polymorphism. Genetics, 123, 596-601.

USDA Forest Service and USDI Bureau of Land Management (2000)
Final supplemental environmental impact statement for amendment to the survey and manage, protection buffer, and other mitigation measures, standards and guides. Vol. 1. USDA Forest Service and USDI Bureau of Land Management, Portland, Oregon.

Verts BJ, Carraway LM (1998) Land Mammals of Oregon. University of California Press, Berkeley, California.

Wall JD (1999) Recombination and the power of statistical tests of neutrality. Genetical Research, 74, 65-79.

Watson DF (1992) Contouring: A Guide to the Analysis and Display of Spatial Data. Pergammon Press, New York.

Watson DF, Philips GM (1985) A refinement of inverse distance weighted interpolation. Geo-processing, 2, 315-327.

Whittaker RH (1961) Vegetation history of the Pacific Coast states and the 'central' significance of the Klamath Region. Madrono, $16,5-23$.

Wilke T, Duncan N (2004) Phylogeographical patterns in the American Pacific Northwest: lessons from the arionid slug Prophysaon coeruleum. Molecular Ecology, 13, 2303-2315.

Zheng X, Arbogast BS, Kenagy GJ (2003) Historical demography and genetic structure of sister species: deermics (Peromyscus) in the North American temperate rain forest. Molecular Ecology, 12, 711-724.

Mark Miller is a Research Assistant Professor at Utah State University who is currently working on a variety of research projects in evolutionary biology. This paper reflects some of his current interests in understanding spatial patterns of genetic diversity across landscapes. M. Renee Bellinger is a molecular ecologist interested in population structure at a number of spatial and temporal scales. Eric Forsman is a population biologist whose research has primarily focused on vertebrates in Pacific Northwest forests of North America. This work was performed in the laboratory of Susan Haig at the U.S. Geological Survey Forest and Rangeland Ecosystem Sciences Center (USGS-FRESC). Dr. Haig's laboratory focuses primarily on evolutionary and anthropogenic processes affecting viability of small populations. 
158 M. P. MiLLER ET AL.

\section{Appendix}

Summary table illustrating D-loop haplotype frequencies from each of the 18 collection areas analysed in this study. Haplotype numbers reflect those indicated on Fig. 3. Information in parentheses refers to data generated for the cytochrome $b$ gene (where appropriate)

\begin{tabular}{|c|c|c|c|c|c|c|c|c|c|c|c|c|c|c|c|c|c|c|c|}
\hline \multirow[b]{2}{*}{ Haplotype } & \multirow[b]{2}{*}{ Accession no. } & \multicolumn{18}{|c|}{ Collection area } \\
\hline & & A & $\mathrm{B}$ & $\mathrm{C}$ & $\mathrm{D}$ & $\mathrm{E}$ & $\mathrm{F}$ & G & $\mathrm{H}$ & I & $\mathrm{J}$ & K & $\mathrm{L}$ & M & $\mathrm{N}$ & $\mathrm{O}$ & $\mathrm{P}$ & $\mathrm{Q}$ & $\mathrm{R}$ \\
\hline 1 & AY836255 (AY338771) & $2(4)$ & & & & & & & & & & & & & & & & & \\
\hline 2 & AY836256 & 2 & & & & & & & & & & & & & & & & & \\
\hline 3 & AY836257 & 2 & & & & & & & & & & & & & & & & & \\
\hline 4 & AY836258 & 1 & & & & & & & & & & & & & & & & & \\
\hline 5 & AY836259 (AY338781) & 1 & & & (1) & & & & & & & & & & & & & & \\
\hline 6 & AY836260 (AY338782) & & 6 & & (1) & & & & & & & & & & & & & & \\
\hline 7 & AY836261 (AY338787) & & & 4 & & & & & & & (1) & & & & 1 & & & & \\
\hline 8 & AY836262 (AY338789) & & & 1 & & & & & & & & & & & & (2) & & & \\
\hline 9 & AY836263 (AY338790) & & & 2 & & & & & & & & & & & & (1) & & & \\
\hline 10 & AY836264 (AY338792) & & & 2 & & & & & & & & & & & & (1) & & & \\
\hline 11 & AY836265 (AY338793) & & & 1 & & & & & & & & & & & & (1) & & & \\
\hline 12 & AY836266 (AY338794) & & & & 2 & (1) & & (1) & & & & & & & & & & & \\
\hline 13 & AY836267 (AY338798) & & & & 2 & (2) & & & & & & & & & & & & & \\
\hline 14 & AY836268 (AY338805) & & & & 1 & & & & & & & & & & & & & (2) & (1) \\
\hline 15 & AY836269 (AY338808) & & & & 5 & & & & & & & & & & & & & & (1) \\
\hline 16 & AY836270 (AY338810) & & & & & 1 & & 6 & & & & & & & & & & & (1) \\
\hline 17 & AY836271 (AY338812) & & & & & 3 & & & & & & & & & & & & & (1) \\
\hline 18 & AY836272 & & & & & 1 & & & & & & & & & & & & & \\
\hline 19 & AY836273 & & & & & 5 & & 1 & & & & & & & & & & & \\
\hline 20 & AY836274 & & & & & & 2 & & & & & & & & & & & & \\
\hline 21 & AY836275 & & & & & & 1 & & & & & & & & & & & & \\
\hline 22 & AY836276 & & & & & & 1 & & & & & & & & & & & & \\
\hline 23 & AY836277 & & & & & & 1 & & & & & & & & & & & & \\
\hline 24 & AY836278 & & & & & & 1 & & & & & & & & & & & & \\
\hline 25 & AY836279 & & & & & & 3 & & & & & & & & & & & & \\
\hline 26 & AY836280 & & & & & & 1 & & & & & & & & & & & & \\
\hline 27 & AY836281 & & & & & & & 2 & & & & & & & & & & & \\
\hline 28 & AY836282 & & & & & & & 1 & & & & & & & & & & & \\
\hline 29 & AY836283 & & & & & & & 1 & & & & & & & & & & & \\
\hline 30 & AY836284 & & & & & & & & 3 & & & & & & & & & & \\
\hline 31 & AY836285 & & & & & & & & 1 & & & & & & & & & & \\
\hline 32 & AY836286 & & & & & & & & 5 & & & & & & & & & & \\
\hline 33 & AY836287 & & & & & & & & 1 & & & & & & & 3 & & & \\
\hline 34 & AY836288 & & & & & & & & 1 & & & & & & & & & & \\
\hline 35 & AY836289 & & & & & & & & 1 & & & 3 & & & 4 & & & & \\
\hline 36 & AY836290 & & & & & & & & & 1 & & & & & & & & & \\
\hline 37 & AY836291 & & & & & & & & & 2 & & & & & & & & & \\
\hline 38 & AY836292 & & & & & & & & & 3 & & 3 & & & & & & & \\
\hline 39 & AY836293 & & & & & & & & & 1 & 2 & 1 & & & & & & & \\
\hline 40 & AY836294 & & & & & & & & & 1 & & & & & & & & & \\
\hline 41 & AY836295 & & & & & & & & & 2 & & & & & & & & & \\
\hline 42 & AY836296 & & & & & & & & & & 2 & & & & & & & & \\
\hline 43 & AY836297 & & & & & & & & & & 1 & & & & & & & & \\
\hline 44 & AY836298 & & & & & & & & & & 3 & & & & & & & & \\
\hline 45 & AY836299 & & & & & & & & & & & 1 & & & & & & & \\
\hline 46 & AY836300 & & & & & & & & & & & 1 & & & & & & & \\
\hline 47 & AY836301 & & & & & & & & & & & 1 & & & & & & & \\
\hline 48 & AY836302 & & & & & & & & & & & & 1 & & & & & & \\
\hline 49 & AY836303 & & & & & & & & & & & & 5 & & & & & & \\
\hline 50 & AY836304 & & & & & & & & & & & & 2 & & & & & & \\
\hline 51 & AY836305 & & & & & & & & & & & & 1 & & & & & & \\
\hline 52 & AY836306 & & & & & & & & & & & & 1 & 1 & & & & & \\
\hline 53 & AY836307 & & & & & & & & & & & & & 3 & & & 3 & & \\
\hline
\end{tabular}


Appendix Continued

\begin{tabular}{|c|c|c|c|c|c|c|c|c|c|c|c|c|c|c|c|c|c|c|c|}
\hline \multirow[b]{2}{*}{ Haplotype } & \multirow[b]{2}{*}{ Accession no. } & \multicolumn{18}{|c|}{ Collection area } \\
\hline & & A & B & $\mathrm{C}$ & $\mathrm{D}$ & $\mathrm{E}$ & $\mathrm{F}$ & G & $\mathrm{H}$ & I & $\mathrm{J}$ & K & $\mathrm{L}$ & M & $\mathrm{N}$ & $\mathrm{O}$ & $\mathrm{P}$ & $\mathrm{Q}$ & $\mathrm{R}$ \\
\hline 54 & AY836308 & & & & & & & & & & & & & 1 & & & & & \\
\hline 55 & AY836309 & & & & & & & & & & & & & 1 & & & & & \\
\hline 56 & AY836310 & & & & & & & & & & & & & & 1 & & & & \\
\hline 57 & AY836311 & & & & & & & & & & & & & & 1 & & & & \\
\hline 58 & AY836312 & & & & & & & & & & & & & & 1 & & & & \\
\hline 59 & AY836313 & & & & & & & & & & & & & & 1 & & & & \\
\hline 60 & AY836314 & & & & & & & & & & & & & & 1 & & 3 & 2 & 1 \\
\hline 61 & AY836315 & & & & & & & & & & & & & & & 2 & & & \\
\hline 62 & AY836316 & & & & & & & & & & & & & & & 1 & & & \\
\hline 63 & AY836317 & & & & & & & & & & & & & & & 1 & & & \\
\hline 64 & AY836318 & & & & & & & & & & & & & & & 1 & & & \\
\hline 65 & AY836319 & & & & & & & & & & & & & & & 1 & & & \\
\hline 66 & AY836320 & & & & & & & & & & & & & & & 1 & & & \\
\hline 67 & AY836321 & & & & & & & & & & & & & & & & 1 & 9 & 4 \\
\hline 68 & AY836322 & & & & & & & & & & & & & & & & 1 & & 1 \\
\hline 69 & AY836323 & & & & & & & & & & & & & & & & 1 & & \\
\hline 70 & AY836324 & & & & & & & & & & & & & & & & & & 2 \\
\hline Total & & 6 & 6 & 10 & 10 & 10 & 10 & 11 & 12 & 10 & 8 & 10 & 10 & 6 & 10 & 10 & 9 & 11 & 8 \\
\hline
\end{tabular}

